\title{
Sequence Analysis of Drug Target Genes with Suicidal Behavior in Bipolar Disorder Patients
}

\author{
Clement C. Zai ${ }^{a-d}$ Arun K. Tiwaria, b Gyneth C. Zai ${ }^{a, b}$ Vincenzo de Luca ${ }^{a-c}$
} Sajid A. Shaikh ${ }^{a}$ Nicole King ${ }^{a} \quad J o h n$ Strauss ${ }^{a-c, ~ e ~ J a m e s ~ L . ~ K e n n e d y ~}{ }^{a-c}$ John B. Vincent ${ }^{b, c, f}$

${ }^{a}$ Neurogenetics Section, Molecular Brain Science, Tanenbaum Centre for Pharmacogenetics, Campbell Family Mental Health Research Institute, Centre for Addiction and Mental Health (CAMH), Toronto, ON, Canada; ${ }^{\mathrm{b}}$ Department of Psychiatry, University of Toronto, Toronto, ON, Canada; ' Institute of Medical Science, University

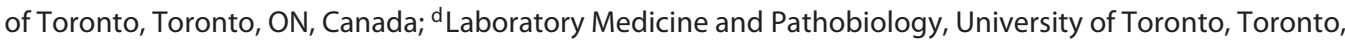
ON, Canada; ${ }^{\mathrm{e}}$ Medical Informatics, Child, Youth, and Family Program, CAMH, Toronto, ON, Canada; ${ }^{\mathrm{f}}$ Molecular Neuropsychiatry and Development (MiND) Laboratory, Campbell Family Mental Health Research Institute, $\mathrm{CAMH}$, Toronto, ON, Canada

\section{Keywords}

Suicide attempt · Sequencing · Bipolar disorder · Genetics · Drug target genes

\footnotetext{
Abstract

Background: A number of genes have been implicated in recent genome-wide association studies of suicide attempt in bipolar disorder. More focused investigation of genes coding for protein targets of existing drugs may lead to drug repurposing for the treatment and/or prevention of suicide. Methods: We analyzed 2,457 DNA variants across 197 genes of interest to GlaxoSmithKline across the pipeline in our sample of European patients suffering from bipolar disorder $(N=219)$. We analyzed these variants for a possible association with the suicide severity score (ranging from suicidal ideation/plan to serious suicide attempt) from the Schedule for Clinical Assessment in Neuropsychiatry. We conducted tests of individual variants and gene-based tests. Results:
}

We found a number of DNA variants in the transforming growth factor beta receptor 1 gene (TGFBR1) to be suggestively associated with suicide severity scores $(p<0.005)$. The gene-based tests also pointed to TGFBR1 to be associated with suicide severity $(p=0.0001)$. However, these findings were not replicated in an independent bipolar disorder sample. Conclusions: We report no significant association between DNA sequences of drug target genes and suicidal behavior. Additional larger sequencing studies could further interrogate associations between variants in drug target genes and suicidal behavior.

(C) 2018 S. Karger AG, Basel

\section{Introduction}

Over 800,000 lives are lost to suicide each year worldwide, and for each completed suicide, there are 20 suicide attempts, making it an important public health issue

\section{KARGER}

(c) 2018 S. Karger AG, Basel

E-Mail karger@karger.com

www.karger.com/mnp
Drs. John B. Vincent or Clement C. Zai

Campbell Family Mental Health Research Institute, CAMH, 250 College Street Toronto, ON M5T1R8 (Canada)

E-Mail john.vincent@camh.ca or clement.zai@camh.ca 
(http://www.who.int/mental_health/prevention/suicide/ suicideprevent/en/). Psychiatric disorders are present in over $90 \%$ of all suicide victims, including bipolar disorder [1], where as many as $8 \%$ of the bipolar disorder patients followed for up to 4 decades died by suicide $[2,3]$.

Family and adoption studies support a genetic component in the susceptibility of suicidal behavior $[4,5$, reviewed in 6]. A review of twin studies estimated the heritability of suicidal behavior to be up to 50\% [7]. Hypothesis-driven studies have identified a number of potential candidate genes. These include the brain-derived neurotrophic factor $(B D N F)$ [8], neurotrophic tyrosine receptor kinase 2 (NTRK2) [9], serotonin 2A receptor (HTR2A) [10], and tryptophan hydroxylase (TPH2) [11]. However, as the effect sizes of markers in these genes have been small, it is likely that suicidal behavior is influenced by many still unidentified genetic factors.

There have been a number of hypothesis-generating genome-wide association studies (GWAS) that investigated the role of common DNA variants in suicidal behavior. Five GWAS of suicide attempt have been reported [12-16]. The acid phosphatase (ACP1) gene reported in a GWAS of suicide attempt in bipolar disorder has recently been replicated in a sample of schizophrenia patients [17]. GWASs of suicidal behavior severity $[6,18]$, suicidal ideation/attempt [19], and suicide attempt/death [20] have also been published. These hypothesis-free studies have yielded a number of intriguing findings that need further validation. GWASs have also implicated neurodevelopment and micro-RNA to play a role in suicidal ideation/behavior [14, 19]. A recent GWAS of suicide attempt in US soldiers indicated a genetic overlap between suicide attempt and bipolar disorder [16]. These GWAS findings will need further validations to confirm.

In 2012, a study reported on sequencing of 202 GlaxoSmithKline (GSK) drug target genes in over 14,000 participants with various medical and psychiatric conditions, including unipolar depression and bipolar disorder, in order to identify therapeutic switching opportunities [21]. While no study-wide significant variants were identified for bipolar disorder, analyzing bipolar disorder-related phenotypes such as suicidal behavior, which is more clinically relevant because of safety risks, may provide a novel avenue for drug repurposing. In the present study, we aimed to investigate the possible association between potential drug target genes and suicidal behavior severity in bipolar disorder patients. We also aimed to test the contribution of all variants as well as only rare variants of each gene to the variance in suicidal behavior severity.

\section{Materials and Methods}

Bipolar I disorder cases in our discovery sample $(N=219)$ were recruited from the $\mathrm{CAMH}$, Toronto, ON, Canada, through advertisements in clinics, family doctor offices, hospitals, and patient support groups [22]. They were at least 18 years of age (average $42.76 \pm 12.37,91$ males, and 128 females), euthymic at the time of the interview with the Schedules for Clinical Assessment in Neuropsychiatry, and self-reported to be of European ethnicity. Bipolar disorder diagnoses were ascertained based on DSM-IV (Diagnostic and Statistical Manual of Mental Disorders, ed 4) or ICD-10 (International Statistical Classification of Diseases and Related Health Problems, 10th revision) criteria, using the computerized algorithm (CATEGO) for the Schedules for Clinical Assessment in Neuropsychiatry 2.1 interview (WHO) through a semi-structured clinical interview. Exclusion criteria were a diagnosis of intravenous drug dependency, reported intravenous drug use, mood-incongruent psychotic symptoms, or manic episodes occurring only in conjunction with or as a result of alcohol, substance abuse, substance dependence, medical illnesses, or medications. Suicidal behavior severity was assessed for the lifetime worst depressive episode by the interviewer using the SCAN Suicide Severity item, with 0 meaning nonsuicidal $(n=71), 1$ denoting suicidal ideation/plan $(n=78), 2$ denoting suicide attempt without serious harm $(n=37)$, 3 indicating suicide attempt with serious harm $(n=11)$, and 4 indicating suicide attempt aiming to end life $(n=22)$. The self-reported European ancestry of the sample was validated with GWAS data from a previous study [23] and is briefly described for the replication sample below.

For targeted sequencing on these 219 bipolar disorder patients, 202 genes were selected from drug target genes of interest to GSK across the pipeline, 70 genes coding for targets under preclinical development, 76 genes encoding targets of drugs in phases I-III, 12 genes encoding targets of marketed drugs (phase IV), and 44 genes coding for targets of drugs terminated after administration to humans [21]. Only genes for which drugs have only 1 known target were selected for sequencing. The names of the selected genes are presented in online supplementary Table 1 (for all online suppl. material, see www.karger.com/doi/10.1159/000488029). Approximately $351 \mathrm{~kb}$ coding and $323 \mathrm{~kb}$ untranslated exon regions plus additional 50 nucleotides of flanking sequence, totaling 863,883 nucleotides, were enriched. The nonoverlapping target regions are provided in online supplementary Table 1. Paired-end DNA sequencing was performed for 48-sample barcoded pools on Illumina Genome Analyzer X2 lanes (San Diego, CA, USA), as previously described [21]. At least half of the samples had $>93 \%$ of the target bases successfully sequenced, with a median sequencing depth of $\times 27$. The sequencing reads were aligned with SOAP (Short Oligonucleotide Analysis Package) [24], and variants were called with SOAPsnp [25]. For initial quality control, variants with singleton heterozygote reads of $<10$, a genotype rate smaller than $50 \%$, or duplicate genotype discordance of $>2 \%$ were excluded. Samples with an average sequencing read depth of $<10$ and a rate of discordant genotypes between sequencing run and available genome-wide panels of $>15 \%$ were excluded.

The replication bipolar disorder sample was collected from the Institute of Psychiatry, London, UK, with the same protocol as our discovery sample $[22,23]$. The replication sample consisted of 362 patients of European ancestry (average age $47.03 \pm$ 11.10 years; 119 males and 243 females). Suicidal behavior sever- 
Table 1. Linear regression analysis of all single-nucleotide variants using PLINK

\begin{tabular}{|c|c|c|c|c|c|c|c|c|c|c|}
\hline CHR & B37 POS & $\mathrm{A} 1$ & rs ID & Beta & $p$ value & Ave. quality & Ave. depth & A1 freq. & Gene & Gene feature \\
\hline 1 & 154550724 & $\mathrm{~T}$ & rs6680410 & 0.074 & $9.87 \mathrm{E}-04$ & 92.20 & 25.12 & 0.085 & CHRNB2 & 3'UTR \\
\hline 10 & 33209266 & G & rs2230396 & -0.063 & $1.34 \mathrm{E}-03$ & 70.96 & 28.21 & 0.105 & ITGB1 & Gly392Gly \\
\hline 1 & 101704532 & $\mathrm{~T}$ & rs3737577 & -0.042 & $1.47 \mathrm{E}-03$ & 87.67 & 33.95 & 0.359 & S1PR1 & 5'UTR \\
\hline 9 & 101916165 & G & rs1590 & 0.042 & $1.49 \mathrm{E}-03$ & 90.34 & 27.08 & 0.286 & TGFBR1 & 3'UTR \\
\hline 21 & 27423547 & $\mathrm{~T}$ & rs41276550 & 0.180 & $1.78 \mathrm{E}-03$ & 97.55 & 27.88 & 0.011 & $A P P$ & Intron \\
\hline 9 & 101908915 & $\mathrm{~A}$ & rs334354 & 0.043 & $2.05 \mathrm{E}-03$ & 93.22 & 30.02 & 0.222 & TGFBR1 & Intron \\
\hline 12 & 121681745 & A & rs75456247 & 0.261 & 4.03E-03 & 95.51 & 31.82 & 0.005 & CAMKK2 & 3'UTR \\
\hline 10 & 33200782 & $\mathrm{~T}$ & rs4587680 & 0.057 & $4.72 \mathrm{E}-03$ & 94.20 & 31.52 & 0.098 & ITGB1 & Intron \\
\hline 17 & 3495391 & $\mathrm{C}$ & rs55916885 & -0.078 & $5.77 \mathrm{E}-03$ & 90.21 & 26.71 & 0.048 & TRPV1 & Gln85Arg \\
\hline
\end{tabular}

The top 10 variants, with the variant ID (rs ID), chromosome (CHR), position in build 37 (B37 POS), location in gene (gene feature), and effect size (Beta) for the test allele (A1), and the frequency of the test allele (A1 freq.).

ity was assessed using the Schedules for Clinical Assessment in Neuropsychiatry suicide severity item, with 0 meaning nonsuicidal $(n=112), 1$ denoting suicidal ideation/plan $(n=136), 2$ denoting suicide attempt without serious harm $(n=60), 3$ indicating suicide attempt with serious harm $(n=13)$, and 4 indicating suicide attempt aiming to end life $(n=41)$. These patients were genotyped on the Illumina HumanHap550 Beadchip at Illumina as described previously [22]. Genotype quality control strategies were described in our GWAS of suicidal behavior severity [23]. Briefly, we applied quality control measures using PLINK (a whole-genome association studies tool set) [26] and R (R Development Core Team, 2008). Briefly, individuals with at least $95 \%$ of the markers genotyped were kept, and markers that were at least $95 \%$ genotyped or had a minor allele frequency of at least $5 \%$ were included. We removed 1 individual of each pair of related individuals (defined as pairs with $\mathrm{PI}^{\mathrm{HAT}}>0.05$ ). Sex was matched with genetic data. Outliers on mean heterozygosity were removed. Markers with genotypes that deviated significantly from the Hardy-Weinberg equilibrium $(p<0.0001)$ were excluded from subsequent analyses. We ran a multidimensional scaling analysis of the genotypes to ascertain the ethnicity of the samples, and we removed the discrete cluster that corresponded to the self-reported Jewish ancestry for all 4 grandparents. After the quality control steps described above, we conducted whole-genome imputation using IMPUTE2 [27] in 5-Mb segments after prephasing in SHAPEIT2 [28], then converted the output to PLINK format using GTOOL (Genetics Software Suite, (c) 2007; The University of Oxford) with a minimum imputation score of 0.9 . Additional quality control (alleles observed, genotyping rate per SNP of at least 95\% and per individual of at least 98\%) was performed in PLINK, resulting in 2,457 single markers from 197 genes.

\section{Statistical Analysis}

Linear regression analyses of 2,457 single markers (with an $r^{2}$ threshold of 0.8 ) with log-transformed SCAN suicide severity scores were conducted on 219 bipolar disorder patients (with available phenotype and covariate data) using PLINK. Covariates included a large number (at least 40) of depressive episodes [29,
30], age, sex, lifetime alcohol (ever drank at least 5 alcoholic drinks every day) [31-33], and the first 2 principal components from the population structure analysis described previously [23]. We used gene- or region-based analysis of variants of intermediate and low frequency to conduct gene-based analysis [34], first involving all variants in each gene region and then involving only variants with a minor allele frequency of $<5 \%$. We have set the two-tailed significance threshold to $0.05 / 2457$ or $2.035 \mathrm{e}-5$ for 2,457 single-marker tests, and to $0.05 / 197$ or $2.54 \mathrm{e}-4$ for 197 gene-based tests.

\section{Results}

The 2,457 single-marker tests did not yield statistically significant findings (Table 1 ). Two of the top 10 variants were located in the transforming growth factor beta receptor 1 (TGFBR1) gene $(p<0.005)$.

Gene-based analysis using all variants yielded a significant finding with the TGFBR1 gene (Table 2; $p=$ 0.0001). We attempted to replicate the TGFRB1 findings from this study using available GWAS data from a replication bipolar disorder sample that was collected from the Institute of Psychiatry in London, UK $[22,23]$. The TGFBR1 gene was not significant in the gene-based analysis in the replication sample.

\section{Discussion}

We report here DNA sequence analysis of drug target genes with the phenotype of suicidal behavior severity. While we found the TGFBR1 gene and individual markers to be significant in the discovery sample, we did not 
Table 2. Analysis of variants with all single-nucleotide variants, and variants with minor allele frequencies of $<5 \%$ using gene- or regionbased analysis of variants of intermediate and low frequency

\begin{tabular}{|c|c|c|c|c|c|c|c|c|c|}
\hline Gene & $\begin{array}{l}\text { Marker } \\
\text { count }\end{array}$ & $\begin{array}{l}\text { Sample } \\
\text { count }\end{array}$ & $\begin{array}{l}\text { Rare variant } \\
\text { sum }\end{array}$ & $\begin{array}{l}\text { Total } \\
\text { MAF }\end{array}$ & $\begin{array}{l}\text { Average } \\
\text { MAF }\end{array}$ & Beta & SE & $Z$ & $p$ \\
\hline \multicolumn{10}{|c|}{ All single-nucleotide variants } \\
\hline ITGAV & 9 & 219 & 275 & 0.7370 & 0.0819 & 0.3607 & 0.1119 & 3.2223 & 0.0015 \\
\hline EVI5 & 27 & 219 & 431 & 1.1227 & 0.0416 & -0.4256 & 0.1431 & -2.9751 & 0.0033 \\
\hline$P D E 4 A$ & 12 & 219 & 99 & 0.2489 & 0.0207 & 0.5244 & 0.1778 & 2.9499 & 0.0035 \\
\hline CCKAR & 12 & 219 & 292 & 0.7397 & 0.0616 & 0.2230 & 0.0905 & 2.4641 & 0.0145 \\
\hline CXCL3 & 3 & 219 & 3 & 0.0069 & 0.0023 & 0.5001 & 0.2224 & 2.2487 & 0.0256 \\
\hline P4HA1 & 10 & 219 & 35 & 0.0847 & 0.0085 & 0.4488 & 0.2025 & 2.2164 & 0.0277 \\
\hline METAP2 & 15 & 219 & 158 & 0.3725 & 0.0248 & -0.3650 & 0.1761 & -2.0724 & 0.0394 \\
\hline KIAA1967 & 22 & 219 & 453 & 1.2497 & 0.0568 & 0.4025 & 0.1987 & 2.0258 & 0.0440 \\
\hline \multicolumn{10}{|c|}{ Variants with minor allele frequencies of $<5 \%$} \\
\hline CXCL3 & 3 & 219 & 3 & 0.0069 & 0.0023 & 0.5001 & 0.2224 & 2.2487 & 0.0256 \\
\hline TACR3 & 7 & 219 & 8 & 0.0183 & 0.0026 & 0.7245 & 0.3237 & 2.2381 & 0.0263 \\
\hline SLC5A1 & 11 & 219 & 14 & 0.0320 & 0.0029 & 0.8066 & 0.3933 & 2.0506 & 0.0415 \\
\hline CHRNA5 & 7 & 219 & 13 & 0.0299 & 0.0043 & -0.5240 & 0.2562 & -2.0456 & 0.0420 \\
\hline $\mathrm{CDH} 2$ & 10 & 219 & 57 & 0.1303 & 0.0130 & 0.2815 & 0.1393 & 2.0208 & 0.0446 \\
\hline
\end{tabular}

Shown are the top genes with $p$ values of $<0.05$, with the number of markers for each gene (marker count), effect sizes (Beta), test statistics $(Z)$, and $p$ values. Rare variant sum, count of rare alleles found in individuals; sample count, number of individuals; total MAF, sum of the minor allele frequencies of all used markers in a given gene region; average MAF, total MAF/marker count.

replicate these findings in an independent sample. The lack of replication could be due to the possibility that the original findings were spurious. It could also be a result of subtle differences between the discovery and replication sample sets. Even though the suicidal behavior severity score distribution did not differ significantly between the samples $(p>0.1)$, compared to the replication sample, the discovery sample had more males (42 vs. $33 \%$; $p<$ 0.05 ), a younger average age (42.76 vs. 47.03 years; $p<$ $0.05)$, and a nonsignificantly higher rate of heavy alcohol use (39 vs. $32 \%$; $p<0.1$ ). Other variables, including environmental stressors, might also have contributed to the mixed findings, though these variables were not available for the present study. It is important to note that we did not have complete data for all genes in the replication sample. For example, half of the top 10 variants, and variants with minor allele frequencies of $<5 \%$, were not available in the imputed GWAS data.

The role of TGFBR1 signaling in the central nervous system is unclear. Together with BDNF, TGFB may regulate DNA methylation in the hippocampus [35]. SB-431542 is a small-molecular inhibitor of TGFBR1 developed by GSK; it has been investigated for antitumor activities, though the effects of this molecule on mood and behavior will need to be explored in preclinical models [36].

The findings from this study should be interpreted with caution due to a number of considerations. First, the sequence data are available only for our moderately sized discovery sample set. Our sample of 219 bipolar disorder patients had over $80 \%$ power to detect an $r^{2}$ of 0.036 (average minor allele frequency for the 2,457 tested variants being 0.077 , additive model, two-tailed alpha 0.05 [37]). Second, we did not have complete data available for the replication data set. Furthermore, our discovery and replication samples may differ in the proportion of patients with bipolar I disorder versus bipolar II disorder. The recently reported incomplete genetic correlation between bipolar I and bipolar II disorders and the potentially different risk factors of suicidal be- 
havior between bipolar I and bipolar II disorders could explain the lack of substantial replication for the majority of our findings $[38,39]$. Furthermore, we did not have detailed information on alcohol use, which might have contributed to the mixed findings. Nonetheless, while our overall findings are negative, additional studies on these and other drug target genes in larger samples are warranted.

\section{Statement of Ethics}

All participants gave informed consent for this study, and all procedures contributing to this work received institutional ethics approval.

\section{Disclosure Statement}

C.C.Z., A.K.T., and J.L.K. applied for patent applications. J.L.K. received honoraria from Roche, Novartis, and Lilly. C.C.Z. received honoraria from WebMD. G.C.Z., V.L., S.A.S., N.K., J.S., J.B.V. have no conflicts of interest to disclose.

\section{References}

1 Mann JJ: A current perspective of suicide and attempted suicide. Ann Intern Med 2002;136: 302-311.

- Angst F, Stassen HH, Clayton PJ, Angst J: Mortality of patients with mood disorders: follow-up over 34-38 years. J Affect Disord 2002;68:167-181.

- 3 Nordentoft M, Mortensen PB, Pedersen CB: Absolute risk of suicide after first hospital contact in mental disorder. Arch Gen Psychiatry 2011;68:1058-1064.

4 Brent DA, Oquendo M, Birmaher B, Greenhill L, Kolko D, Stanley B, Zelazny J, Brodsky B, Bridge J, Ellis S, Salazar JO, Mann JJ: Familial pathways to early-onset suicide attempt: risk for suicidal behavior in offspring of mood-disordered suicide attempters. Arch Gen Psychiatry 2002;59:801-807.

5 Johnson BA, Brent DA, Bridge J, Connolly J: The familial aggregation of adolescent suicide attempts. Acta Psychiatr Scand 1998;97:1824.

6 Zai CC, de Luca V, Strauss J, Tong RP, Sakinofsky I, Kennedy JL: Genetic factors and suicidal behavior; in Dwivedi Y (ed): The Neurobiological Basis of Suicide. Boca Raton, CRC Press, 2012.

7 Voracek M, Loibl LM: Genetics of suicide: a systematic review of twin studies. Wien Klin Wochenschr 2007;119:463-475.

8 Zai CC, Manchia M, De Luca V, Tiwari AK, Chowdhury NI, Zai GC, Tong RP, Yilmaz Z, Shaikh SA, Strauss J, Kennedy JL: The brainderived neurotrophic factor gene in suicidal behaviour: a meta-analysis. Int J Neuropsychopharmacol 2012;15:1037-1042.

-9 Kohli MA, Salyakina D, Pfennig A, Lucae S, Horstmann S, Menke A, Kloiber S, Hennings J, Bradley BB, Ressler KJ, Uhr M, MullerMyhsok B, Holsboer F, Binder EB: Association of genetic variants in the neurotrophic receptor-encoding gene NTRK2 and a lifetime history of suicide attempts in depressed patients. Arch Gen Psychiatry 2010;67:348359.

10 Wang JY, Jia CX, Lian Y, Sun SH, Lyu M, Wu A: Association of the HTR2A 102T/C polymorphism with attempted suicide: a metaanalysis. Psychiatr Genet 2015;25:168-177.
11 Gonzalez-Castro TB, Juarez-Rojop I, LopezNarvaez ML, Tovilla-Zarate CA: Association of TPH-1 and TPH-2 gene polymorphisms with suicidal behavior: a systematic review and meta-analysis. BMC Psychiatry 2014;14:196.

12 Mullins N, Perroud N, Uher R, Butler AW, Cohen-Woods S, Rivera M, Malki K, Euesden J, Power RA, Tansey KE, Jones L, Jones I, Craddock N, Owen MJ, Korszun A, Gill M, Mors O, Preisig M, Maier W, Rietschel M, Rice JP, Muller-Myhsok B, Binder EB, Lucae S, Ising M, Craig IW, Farmer AE, McGuffin P, Breen G, Lewis CM: Genetic relationships between suicide attempts, suicidal ideation and major psychiatric disorders: a genome-wide association and polygenic scoring study. Am J Med Genet B Neuropsychiatr Genet 2014;165B:428-437.

13 Perlis RH, Huang J, Purcell S, Fava M, Rush AJ, Sullivan PF, Hamilton SP, McMahon FJ, Schulze TG, Potash JB, Zandi PP, Willour VL, Penninx BW, Boomsma DI, Vogelzangs N, Middeldorp CM, Rietschel M, Nothen M, Cichon S, Gurling H, Bass N, McQuillin A, Hamshere M, Craddock N, Sklar P, Smoller JW: Genome-wide association study of suicide attempts in mood disorder patients. Am J Psychiatry 2010;167:1499-1507.

14 Sokolowski M, Wasserman J, Wasserman D: Polygenic associations of neurodevelopmental genes in suicide attempt. Mol Psychiatry 2016;21:1381-1390.

15 Willour VL, Seifuddin F, Mahon PB, Jancic D, Pirooznia M, Steele J, Schweizer B, Goes FS, Mondimore FM, Mackinnon DF, Perlis RH, Lee PH, Huang J, Kelsoe JR, Shilling PD, Rietschel M, Nothen M, Cichon S, Gurling H, Purcell S, Smoller JW, Craddock N, DePaulo JR, Jr., Schulze TG, McMahon FJ, Zandi PP, Potash JB: A genome-wide association study of attempted suicide. Mol Psychiatry 2012;17: 433-444.

16 Stein MB, Ware EB, Mitchell C, Chen CY, Borja S, Cai T, Dempsey CL, Fullerton CS, Gelernter J, Heeringa SG, Jain S, Kessler RC, Naifeh JA, Nock MK, Ripke S, Sun X, Beckham JC, Kimbrel NA, Ursano RJ, Smoller JW: Genomewide association studies of suicide attempts in US soldiers. Am J Med Genet B Neuropsychiatr Genet 2017;174:786-797.
17 Li J, Yoshikawa A, Meltzer HY: Replication of rs300774, a genetic biomarker near ACP1, associated with suicide attempts in patients with schizophrenia: Relation to brain cholesterol biosynthesis. J Psychiatr Res 2017;94:54-61.

18 Schosser A, Butler AW, Ising M, Perroud N, Uher R, Ng MY, Cohen-Woods S, Craddock N, Owen MJ, Korszun A, Jones L, Jones I, Gill M, Rice JP, Maier W, Mors O, Rietschel M, Lucae S, Binder EB, Preisig M, Perry J, Tozzi F, Muglia P, Aitchison KJ, Breen G, Craig IW, Farmer AE, Muller-Myhsok B, McGuffin P, Lewis CM: Genomewide association scan of suicidal thoughts and behaviour in major depression. PLoS One 2011;6:e20690.

19 Pulay AJ, Rethelyi JM: Multimarker analysis suggests the involvement of BDNF signaling and microRNA biosynthesis in suicidal behavior. Am J Med Genet B Neuropsychiatr Genet 2016;171:763-776.

20 Galfalvy H, Haghighi F, Hodgkinson C, Goldman D, Oquendo MA, Burke A, Huang YY, Giegling I, Rujescu D, Bureau A, Turecki G, Mann JJ: A genome-wide association study of suicidal behavior. Am J Med Genet B Neuropsychiatr Genet 2015;168:557-563.

21 Nelson MR, Wegmann D, Ehm MG, Kessner D, St Jean P, Verzilli C, Shen J, Tang Z, Bacanu SA, Fraser D, Warren L, Aponte J, Zawistowski M, Liu X, Zhang H, Zhang Y, Li J, Li Y, Li L, Woollard P, Topp S, Hall MD, Nangle K, Wang J, Abecasis G, Cardon LR, Zollner S, Whittaker JC, Chissoe SL, Novembre J, Mooser V: An abundance of rare functional variants in 202 drug target genes sequenced in 14,002 people. Science 2012;337:100-104.

22 Scott LJ, Muglia P, Kong XQ, Guan W, Flickinger M, Upmanyu R, Tozzi F, Li JZ, Burmeister M, Absher D, Thompson RC, Francks C, Meng F, Antoniades A, Southwick AM, Schatzberg AF, Bunney WE, Barchas JD, Jones EG, Day R, Matthews K, McGuffin P, Strauss JS, Kennedy JL, Middleton L, Roses AD, Watson SJ, Vincent JB, Myers RM, Farmer AE, Akil H, Burns DK, Boehnke M: Genome-wide association and meta-analysis of bipolar disorder in individuals of European ancestry. Proc Natl Acad Sci USA 2009;106: 7501-7506. 
23 Zai CC, Goncalves VF, Tiwari AK, Gagliano SA, Hosang G, de Luca V, Shaikh SA, King N, Chen Q, Xu W, Strauss J, Breen G, Lewis CM, Farmer AE, McGuffin P, Knight J, Vincent JB, Kennedy JL: A genome-wide association study of suicide severity scores in bipolar disorder. J Psychiatr Res 2015;65:23-29.

24 Li R, Li Y, Kristiansen K, Wang J: SOAP: short oligonucleotide alignment program. Bioinformatics 2008;24:713-714.

25 Li R, Li Y, Fang X, Yang H, Wang J, Kristiansen K: SNP detection for massively parallel whole-genome resequencing. Genome Res 2009;19:1124-1132.

26 Purcell S, Neale B, Todd-Brown K, Thomas L, Ferreira MA, Bender D, Maller J, Sklar P, de Bakker PI, Daly MJ, Sham PC: PLINK: a tool set for whole-genome association and population-based linkage analyses. Am J Hum Genet 2007;81:559-575.

27 Howie B, Fuchsberger C, Stephens M, Marchini J, Abecasis GR: Fast and accurate genotype imputation in genome-wide association studies through pre-phasing. Nat Genet 2012;44:955-959.

28 Delaneau O, Howie B, Cox AJ, Zagury JF, Marchini J: Haplotype estimation using sequencing reads. Am J Hum Genet 2013;93: 687-696.

29 Ahrens B, Berghofer A, Wolf T, Muller-Oerlinghausen B: Suicide attempts, age and duration of illness in recurrent affective disorders. J Affect Disord 1995;36:43-49.
30 Zisook S, Lesser I, Stewart JW, Wisniewski SR, Balasubramani GK, Fava M, Gilmer WS, Dresselhaus TR, Thase ME, Nierenberg AA, Trivedi MH, Rush AJ: Effect of age at onset on the course of major depressive disorder. Am J Psychiatry 2007;164:1539-1546.

-31 Brady J: The association between alcohol misuse and suicidal behaviour. Alcohol Alcohol 2006;41:473-478.

- 32 Pompili M, Serafini G, Innamorati M, Dominici G, Ferracuti S, Kotzalidis GD, Serra G, Girardi P, Janiri L, Tatarelli R, Sher L, Lester D: Suicidal behavior and alcohol abuse. Int J Environ Res Public Health 2010;7:1392-1431.

33 Sher L: Alcohol consumption and suicide. QJM 2006;99:57-61.

34 Morris AP, Zeggini E: An evaluation of statistical approaches to rare variant analysis in genetic association studies. Genet Epidemiol 2010;34:188-193.

35 Grassi D, Franz H, Vezzali R, Bovio P, Heidrich S, Dehghanian F, Lagunas N, Belzung C, Krieglstein K, Vogel T: Neuronal activity, TGF $\beta$-signaling and unpredictable chronic stress modulate transcription of Gadd45 family members and DNA methylation in the hippocampus. Cereb Cortex 2017; 27:4166-4181.
36 Inman GJ, Nicolas FJ, Callahan JF, Harling JD, Gaster LM, Reith AD, Laping NJ, Hill CS: SB-431542 is a potent and specific inhibitor of transforming growth factor-beta superfamily type I activin receptor-like kinase (ALK) receptors ALK4, ALK5, and ALK7. Mol Pharmacol 2002;62:65-74.

37 Gauderman WJ, Morrison JM: QUANTO 1.1: A computer program for power and sample size calculations for genetic-epidemiology studies, 2006. http://hydra.usc.edu/gxe.

38 Charney AW, Ruderfer DM, Stahl EA, Moran JL, Chambert K, Belliveau RA, Forty L, Gordon-Smith K, Di Florio A, Lee PH, Bromet EJ, Buckley PF, Escamilla MA, Fanous AH, Fochtmann LJ, Lehrer DS, Malaspina D, Marder SR, Morley CP, Nicolini H, Perkins DO, Rakofsky JJ, Rapaport MH, Medeiros H, Sobell JL, Green EK, Backlund L, Bergen SE, Jureus A, Schalling M, Lichtenstein P, Roussos P, Knowles JA, Jones I, Jones LA, Hultman CM, Perlis RH, Purcell SM, McCarroll SA, Pato CN, Pato MT, Craddock N, Landen M, Smoller JW, Sklar P: Evidence for genetic heterogeneity between clinical subtypes of bipolar disorder. Transl Psychiatry 2017;7:e993.

39 Valtonen H, Suominen K, Mantere O, Leppamaki S, Arvilommi P, Isometsa ET: Suicidal ideation and attempts in bipolar I and II disorders. J Clin Psychiatry 2005;66:14561462. 